Diabetologia (1994) 37: 75-81

Diabetologia

(C) Springer-Verlag 1994

\title{
Effect of hyperglycaemia on gallbladder motility in Type 1 (insulin-dependent) diabetes mellitus
}

\author{
S. Y. de Boer ${ }^{1}$, A. A.M.Masclec ${ }^{1}$, W.F.Lam ${ }^{1}$, H.H.P.J. Lemkes ${ }^{2}$, J.Schipper ${ }^{3}$, M. Fröhlich ${ }^{4}$,J. B. M.J. Jansen ${ }^{1}$, \\ C.B.H.W.Lamers ${ }^{1}$ \\ ${ }^{1}$ Department of Gastroenterology and Hepatology, University Hospital, Leiden, The Netherlands \\ ${ }^{2}$ Department of Endocrinology and Metabolic Diseases, University Hospital, Leiden, The Netherlands \\ ${ }^{3}$ Department of Radiology, University Hospital, Leiden, The Netherlands \\ ${ }^{4}$ Department of Clinical Chemistry, University Hospital, Leiden, The Netherlands
}

Summary Patients with diabetes mellitus are at increased risk of developing gallstones. This has been attributed, among other factors, to alterations in gallbladder motility in the presence of autonomic neuropathy. Since high blood glucose concentrations impair gastric emptying in diabetic patients, we have investigated the effect of acute hyperglycaemia on gallbladder motility. Seven Type 1 (insulin-dependent) diabetic patients were studied twice during euglycaemia (blood glucose $5 \mathrm{mmol} / \mathrm{l}$ ) and hyperglycaemia (blood glucose $15 \mathrm{mmol} / \mathrm{l}$ ) using a clamp technique. In addition, seven healthy volunteers were studied during euglycaemia and hyperglycaemia. Gallbladder volumes, measured with ultrasonography, were studied before and during infusion of step-wise increasing doses of cholecystokinin-33, 0.25, 0.5 and 1.0 Ivy Dog Unit $\cdot \mathrm{kg}^{-1} \cdot \mathrm{h}^{-1}$, each dose for $30 \mathrm{~min}$. Mean basal gallbladder volumes were not significantly different in the four experiments. Administration of cholecystokinin resulted in significant $(p<0.05)$ dose-dependent reductions in gallbladder volume in all experiments. During euglycaemia the gallbladder contraction in diabetic patients was not significantly different from the control subjects. During hyperglycaemia the gallbladder contraction in the diabetic patients was significantly $(p<0.05)$ reduced compared to euglycaemia only during infusion of 0.25 Ivy Dog Unit $\cdot \mathrm{kg}^{-1} \cdot \mathrm{h}^{-1}$ of cholecystokinin $(19 \pm 6 \%$ vs $33 \pm 6 \%$ ). Compared to euglycaemia, during hyperglycaemia the gallbladder contraction in the control subjects was significantly $(p<0.05)$ reduced during infusion of $0.25,0.5$ and 1.0 Ivy Dog Unit $\cdot \mathrm{kg}^{-1} \cdot \mathrm{h}^{-1}$ of cholecystokinin $(14 \pm 4 \%$ vs $31 \pm 3 \% ; 42 \pm 6 \%$ vs $65 \pm 5 \% ; 74 \pm 4 \%$ vs $90 \pm 3 \%$, respectively). It is concluded that during euglycaemia the gallbladder contraction in response to cholecystokinin in Type 1 diabetic patients is not significantly different from control subjects. During hyperglycaemia the gallbladder contraction in response to $0.25 \mathrm{Ivy}$ Dog Unit $\cdot \mathrm{kg}^{-1} \cdot \mathrm{h}^{-1}$ cholecystokinin, leading to cholecystokinin levels as observed after ingestion of a light meal, is significantly reduced in Type 1 diabetic patients. [Diabetologia (1994) 37:75-81]

Key words Gallbladder emptying, hyperglycaemia, cholecystokinin, Type 1 (insulin-dependent) diabetes mellitus, autonomic neuropathy.
Patients with diabetes mellitus are thought to have an increased risk of developing gallstones [1-3]. The pathogenesis of gallstones is multifactorial. Apart from cholesterol supersaturation and the presence of crystal

Received 22 June 1992

and in revised form: 22 July 1993

Corresponding author: Dr. A. A.M.Masclee, Department of Gastroenterology and Hepatology, University Hospital, Building 1, C4-P, P.O. Box 9600, NL-2300 RC Leiden, The Netherlands nucleation promoting factors, impaired gallbladder motility is considered to be an important factor contributing to the formation of gallstones especially in diabetic patients $[4,5]$. Although previous studies have shown that gallbladder emptying is impaired in patients with diabetes [6-9], in other studies gallbladder contraction in diabetic patients was not significantly different from control subjects $[10,11]$. It has been suggested that impaired gallbladder emptying in diabetes is related to the presence of autonomic neuropathy $[6,9,10]$.

Recently several studies have pointed to the effect of blood glucose concentrations in the regulation of 
Table 1. Clinical features of the Type 1 diabetic patients

\begin{tabular}{lllllll}
\hline Patient & $\begin{array}{l}\text { Age } \\
\text { (years) }\end{array}$ & $\begin{array}{l}\text { Duration } \\
\text { of diabetes } \\
\text { (years) }\end{array}$ & Sex & $\begin{array}{l}\text { Serum creatinine } \\
\text { (normal: } 70-133 \\
\mu m o l / 1)\end{array}$ & $\begin{array}{l}\mathrm{HbA}_{\mathrm{cc}} \\
\text { (normal: } \\
<6.7 \%)\end{array}$ & $\begin{array}{l}\text { BMI } \\
\left(\mathrm{kg} / \mathrm{m}^{2}\right)\end{array}$ \\
\hline 1 & 19 & 9 & $\mathrm{~m}$ & 76 & 6.6 & 24.3 \\
2 & 21 & 1 & $\mathrm{~m}$ & 102 & 9.0 & 21.9 \\
3 & 33 & 13 & $\mathrm{~m}$ & 78 & 8.1 & 22.2 \\
4 & 24 & 11 & $\mathrm{~m}$ & 87 & 7.0 & 24.7 \\
5 & 38 & 5 & $\mathrm{~m}$ & 74 & 6.3 & 21.4 \\
6 & 26 & 2 & $\mathrm{~m}$ & 73 & 7.9 & 27.5 \\
7 & 24 & 18 & $\mathrm{f}$ & 83 & & \\
\hline
\end{tabular}

gastrointestinal motility [12-16]. During acute hyperglycaemia gastric emptying was found to be delayed in healthy subjects and in patients with Type 1 (insulindependent) and Type 2 (non-insulin-dependent) diabetes [12-15]. Little is known about the effect of hyperglycaemia on gallbladder motility in diabetic patients.

Therefore, in the present study we have investigated the effect of hyperglycaemia on gallbladder motility in Type 1 diabetic patients and control subjects. To exclude a possible effect of autonomic neuropathy on gallbladder motility only Type 1 diabetic patients with no clinical signs of autonomic neuropathy were investigated. Gallbladder emptying in response to i.v. infusion of graded doses of cholecystokinin (CCK) was measured during stabilized euglycaemia (blood glucose concentration $5 \mathrm{mmol} / \mathrm{l}$ ) and stabilized hyperglycaemia (blood glucose concentration $15 \mathrm{mmol} / \mathrm{l}$ ).

\section{Subjects and methods}

\section{Patients}

Seven patients with Type 1 diabetes (six male, one female; age 19-38 years; body mass index $24.0 \pm 0.9 \mathrm{~kg} / \mathrm{m}^{2}$ ) and seven healthy volunteers (six male, one female; age 20-28 years; body mass index $22.8 \pm 0.5 \mathrm{~kg} / \mathrm{m}^{2}$ ) participated in the study. The clinical data of the patients are shown in Table 1 . Patients were excluded from the study if they were taking other medication apart from insulin. None of the patients or volunteers had a history of gallstones, gastrointestinal disease or surgery. The presence of gallstones was excluded by ultrasonography. Only patients without clinical signs of autonomic neuropathy and normal cardiovascular reflex tests according to Ewing and Clark [17] were induced in the study. The study protocol had been approved by the Ethics Committee of the Leiden University Hospital. Informed consent was obtained from each individual.

\section{Protocol}

Both the diabetic patients and the healthy subjects were studied two times after an overnight fast with an interval of at least 7 days. The order of the euglycaemic and hyperglycaemic clamp experiments was randomized. Blood glucose concentrations were maintained in either the euglycaemic range $(5 \pm 1 \mathrm{mmol} / 1)$ or the hyperglycaemic range $(15 \pm 1 \mathrm{mmol} / \mathrm{l})$ using a modified clamp technique [18]. All experiments were started at 09.00 hours after an overnight fast. An i. v. cannula was inserted into an antecubital vein of one arm for blood sampling. A second i. v. cannula was positioned in the other arm for infusion of insulin or glucose or both. After basal blood samples were drawn and gallbladder images with ultrasonography were obtained, the glucose clamp was initiated between time -75 and $-60 \mathrm{~min}$. At time 0 min a continuous infusion of CCK-33 (Ferring, Malmo, Sweden) was started. CCK was administered for $90 \mathrm{~min}$ in stepwise increasing doses of $0.25,0.5$ and 1.0 Ivy Dog Unit per Kg per hour, (IDU $\cdot \mathrm{kg}^{-1} \cdot \mathrm{h}^{-1}$ ) each dose for $30 \mathrm{~min}$. Previous studies have shown that the plasma CCK concentrations obtained with these doses correspond with plasma $\mathrm{CCK}$ concentrations as found after ingestion of a light, a normal and a fat meal, respectively [19]. Gallbladder imaging was performed with real-time ultrasonography every $15 \mathrm{~min}$. Blood samples for assay of CCK, pancreatic polypeptide (PP), glucagon and insulin were taken every time a gallbladder image was obtained. Blood glucose concentrations were measured every 2.5 to $5 \mathrm{~min}$.

\section{Glucose clamp technique}

Bolus injections of insulin (Actrapid Human; CSL, Novo, Zoeterwoude, The Netherlands) or bolus i. v. injections and infusions of $20 \%$ glucose were administered according to the protocol. The amount of the bolus injections of insulin was 1-4 IU, depending on the actual and the proposed blood glucose concentration and the weight of the patient according to previously published formula [18]. The amount of glucose administered was calculated from the body weight. After the bolus injection, the rate of glucose infusion or insulin administration was adjusted to maintain a blood glucose concentration of approximately $15 \mathrm{mmol} / \mathrm{l}$ or $5 \mathrm{mmol} / \mathrm{l}$, according to the protocol. Measurement of blood glucose concentration, every 2.5 to $5 \mathrm{~min}$, was performed with the glucose oxidase method (Beckman Glucose Analyser; Beckman Instruments, Palo Alto, Calif, USA).

\section{Measurement of gallbladder volume}

Gallbladder volumes measured with real-time ultrasonography (Technicare, $3.5 \mathrm{MHz}$ transducer) were calculated by the sum of cylinders method using a computerized system $[20,21]$. In this method the longitudinal image of the gallbladder is divided into a series of equal height, with diameters perpendicular to the longitudinal axis of the gallbladder image. The uncorrected volume is the sum of volumes of these separate cylinders. To correct for the displacement of the longitudinal image of the gallbladder from the central axis, a correction factor is calculated from the longitudinal and transverse scans of the gallbladder. Gallbladder volume is calculated by multiplication of the uncorrected volume with the square of the correction factor. The mean of the 
two measurements was used for analysis. The assumptions and the mathematical formula used to calculate gallbladder volume have been described and validated previously $[20,21]$.

\section{Assays of CCK, pancreatic polypeptide (PP), insulin and glucagon}

Plasma CCK was measured by a sensitive and specific RIA using antibody $\mathrm{T} 204[22,23]$. This antibody binds to all carboxy-terminal CCK peptides containing the sulphated tyrosyl region. The detection limit of the assay was $0.5 \mathrm{pmol} / \mathrm{l}$ plasma. The intraassay variation ranged from 4.6 to $11.5 \%$ and the inter-assay variation from 11.3 to $26.1 \%$ [23]. Plasma PP concentrations were measured by a sensitive and specific RIA, as described previously [24]. Plasma insulin and plasma glucagon were measured with an RIA as described previously [25]. Plasma glucagon concentrations were determined in duplicate by RIA (Daiichi, Tokyo, Japan). The limit of detection was $15 \mathrm{pg} / \mathrm{ml}$, with an interassay coefficient of variation of $8.5 \%$.

\section{Statistical analysis}

The results are expressed as mean \pm SEM. The gallbladder volumes are expressed in cubic centimeters $\left(\mathrm{cm}^{3}\right)$ or as the percentages considering the gallbladder volume at the start of the CCK infusion as $100 \%$ (time $0 \mathrm{~min}$ ). The integrated incremental PP secretion in response to CCK was determined by calculating the area under the plasma concentration-time curve after subtraction of the basal value at time $0 \mathrm{~min}$.

Data were analysed for the significance of differences by analysis of variance (ANOVA). When this indicated a probability of less than 0.05 for the null hypothesis, Student Newman Keuls analyses were performed to determine which values differed significantly. The significance level was set at $p<0.05$.

\section{Results}

\section{Blood glucose concentrations}

In the diabetic patients mean fasting blood glucose concentrations were $9.6 \pm 1.2 \mathrm{mmol} / \mathrm{l}$ in the euglycaemic experiment and $12.7 \pm 1.4 \mathrm{mmol} / \mathrm{l}$ in the hyperglycaemic experiment (Fig.1). In the euglycaemic experiment blood glucose concentrations were stabilized at $5 \mathrm{mmol} / \mathrm{l}$ starting from $30 \mathrm{~min}$ after the administration of insulin. In the hyperglycaemic experiment stabilisation of the blood glucose levels was achieved within $15 \mathrm{~min}$. Basal blood glucose concentrations in the control subjects were $5.1 \pm 0.2 \mathrm{mmol} / 1$ in the normoglycaemic experiment and $5.0 \pm 0.3$ in the hyperglycaemic experiment. Mean blood glucose levels reached during clamping are shown in Figure 1.

\section{Gallbladder volumes}

In the diabetic patients basal gallbladder volumes were not significantly different between the two experiments: $24 \pm 4 \mathrm{~cm}^{3}$ (euglycaemia) and $22 \pm 5 \mathrm{~cm}^{3}$ (hyper-

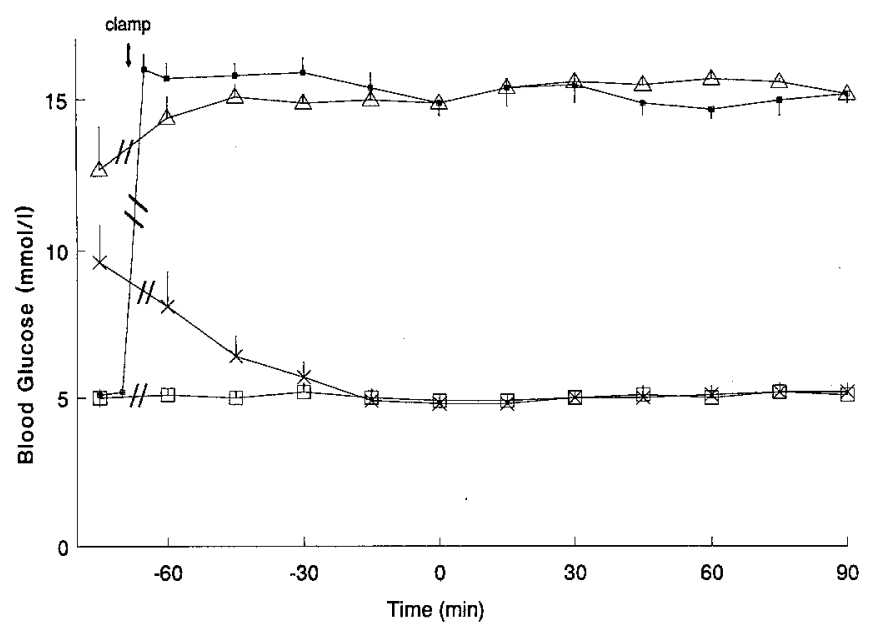

Fig.1. Blood glucose concentrations (mmol/l, mean $\pm \mathrm{SEM}$ ) during euglycaemia (crosses) and hyperglycaemia of $15 \mathrm{mmol} / \mathrm{h}$ (triangles) in seven diabetic patients, and during euglycaemia (squares) and hyperglycaemia (small squares) in seven control subjects
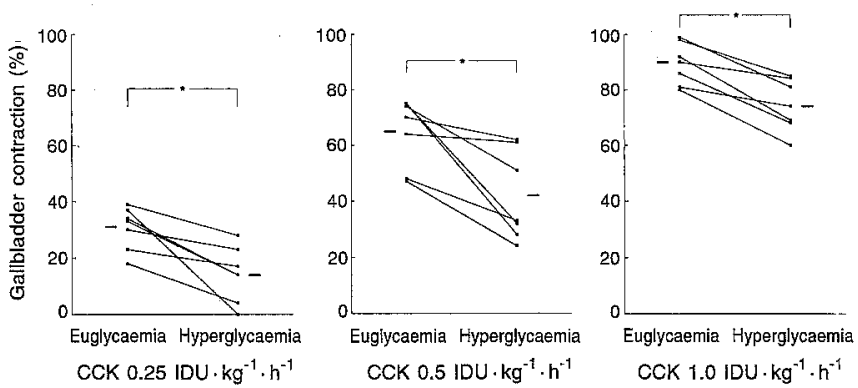

Fig. 2. Individual data and mean of gallbladder contraction (\%) during euglycaemia and hyperglycaemia in control subjects after infusion of cholecystokinin (CCK)-33 0.25, 0.5 and 1.0 Ivy Dog Unit (IDU) $\cdot \mathrm{kg}^{-1} \cdot \mathrm{h}^{-1}(* p<0.05)$

glycaemia). Mean basal gallbladder volumes in the control subjects were $21 \pm 2 \mathrm{~cm}^{3}$ (euglycaemia) and $23 \pm 3 \mathrm{~cm}^{3}$ (hyperglycaemia). Gallbladder volumes did not significantly change during the basal $60 \mathrm{~min}$ before CCK infusion. At time 0 min gallbladder volumes in the diabetic patients (hyperglycaemia $23 \pm 4 \mathrm{~cm}^{3}$; euglycaemia $25 \pm 3 \mathrm{~cm}^{3}$ ) were not significantly different from control subjects (hyperglycaemia $25 \pm 3 \mathrm{~cm}^{3}$; euglycaemia $23 \pm 2 \mathrm{~cm}^{3}$ ). Administration of stepwise increasing doses of CCK-33 $0.25,0.5$ and 1.0 IDU. $\mathrm{kg}^{-1} \cdot \mathrm{h}^{-1}$ resulted in significant reductions in gallbladder volume in the diabetic patients from $100 \%$ to $67 \pm$ $6 \%(p<0.05), 29 \pm 5 \%(p<0.05)$ and $7 \pm 1 \%(p<$ 0.05 ), respectively during euglycaemia, and from $100 \%$ to $81 \pm 6 \%(p<0.05), 34 \pm 4 \%(p<0.05)$, and $11 \pm 1 \%$ $(p<0.05)$, respectively during hyperglycaemia. In the control subjects gallbladder volumes decreased significantly in response to infusion of $0.25,0.5$ and $1.0 \mathrm{IDU} \cdot \mathrm{kg}^{-1} \cdot \mathrm{h}^{-1}$ of CCK-33 from $100 \%$ to $69 \pm 3 \%$ $(p<0.05), 35 \pm 5 \%(p<0.05)$ and $10 \pm 3 \%(p<0.05)$, respectively during euglycaemia and from $100 \%$ to 
S.Y. de Boer et al.: Gallbladder motility during hyperglycaemia in diabetes mellitus

Table 2. Plasma CCK concentrations (pmol/1, mean \pm SEM) before and during infusion of stepwise increasing doses of CCK-33

\begin{tabular}{lccccc}
\hline $\begin{array}{l}\text { CCK-33 infusion rate } \\
\text { (IDU } \cdot \mathrm{kg}^{-1} \cdot \mathbf{h}^{-1} \text { ) }\end{array}$ & \multicolumn{2}{l}{ Control subjects } & & \multicolumn{2}{l}{ Diabetic patients } \\
\cline { 2 - 3 } \cline { 5 - 6 } & Euglycaemia & Hyperglycaemia & & Euglycaemia & Hyperglycaemia \\
\hline basal & $3.3 \pm 0.3$ & $3.7 \pm 0.4$ & & $4.1 \pm 0.5$ & $3.8 \pm 0.8$ \\
0.25 & $4.7 \pm 0.3^{*}$ & $4.7 \pm 0.4^{*}$ & & $5.3 \pm 0.5^{*}$ & $4.9 \pm 0.7^{*}$ \\
0.5 & $7.5 \pm 0.5^{*}$ & $6.9 \pm 0.5^{*}$ & & $8.0 \pm 0.6^{*}$ & $7.7 \pm 0.7^{*}$ \\
1.0 & $11.1 \pm 0.8^{*}$ & $11.8 \pm 0.8^{*}$ & & $13.4 \pm 1.0^{*}$ & $12.7 \pm 0.9^{*}$ \\
\hline
\end{tabular}

${ }^{*} p<0.05$ compared to basal
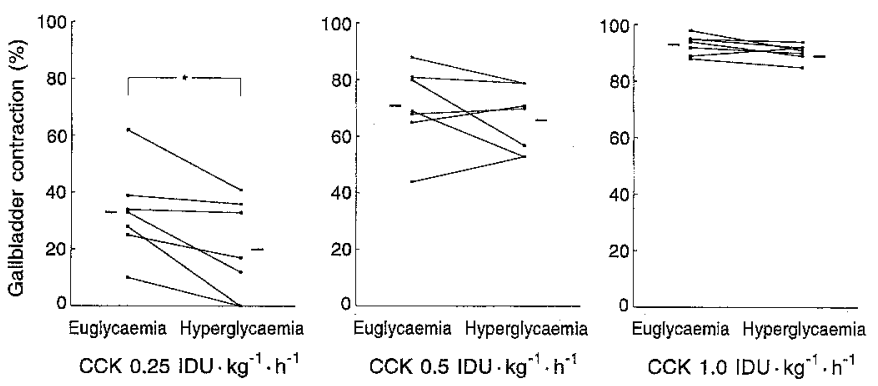

Fig. 3. Individual data and mean of gallbladder contraction (\%) during euglycaemia and hyperglycaemia in diabetic patients after infusion of cholecystokinin (CCK)-33 0.25, 0.5 and 1.0 Ivy Dog Unit (IDU) $\cdot \mathrm{kg}^{-1} \cdot \mathrm{h}^{-1}(* p<0.05)$
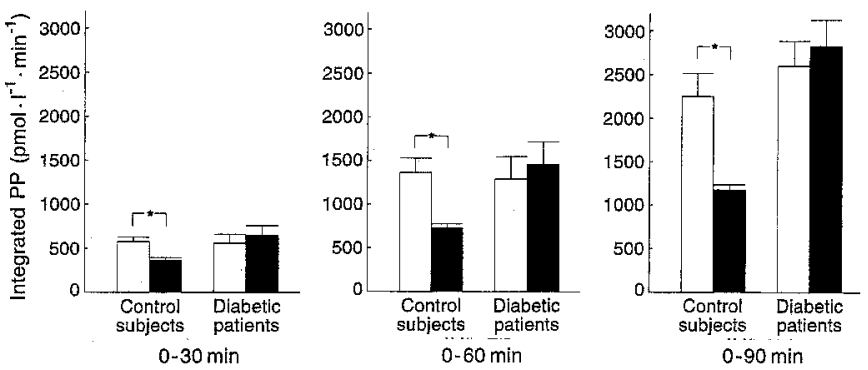

Fig. 4. Integrated incremental plasma pancreatic polypeptide (PP) secretion ( $\mathrm{pmol} \cdot 1^{-1} \cdot \mathrm{min}^{-1}$, mean $\pm \mathrm{SEM}$ ) in response to cholecystokinin infusion during euglycaemia (open bars) and hyperglycaemia (filled bars) in the control subjects, and during euglycaemia (open bars) and hyperglycaemia (filled bars) in the diabetic patients $(* p<0.05)$

$86 \pm 4 \%(p<0.05), 58 \pm 6 \%(p<0.05)$ and $26 \pm 4 \%$ $(p<0.05)$, respectively during hyperglycaemia. In the control subjects the gallbladder contraction in response to $0.25,0.5$ and $1.0 \mathrm{IDU} \cdot \mathrm{kg}^{-1} \cdot \mathrm{h}^{-1}$ of CCK was significantly $(p<0.05)$ reduced during the hyperglycaemic experiment compared to euglycaemia (Fig. 2), whereas in the diabetic patients the gallbladder contraction during hyperglycaemia was only significantly reduced compared to euglycaemia in response to an infusion of $0.25 \mathrm{IDU} \cdot \mathrm{kg}^{-1} \cdot \mathrm{h}^{-1}$ of CCK-33 (Fig. 3). During euglycaemia no significant differences in gallbladder contraction were observed between the diabetic patients and the control subjects. During hyperglycaemia the gallbladder contraction in response to 0.25 IDU $\cdot \mathrm{kg}^{-1} \cdot \mathrm{h}^{-1}$ of CCK was not significantly different between diabetic patients and control subjects. However, during hyperglycaemia the gallbladder contrac- tion in response to 0.5 and $1.0 \mathrm{IDU} \cdot \mathrm{kg}^{-1} \cdot \mathrm{h}^{-1}$ of CCK33 was significantly $(p<0.05)$ reduced in control subjects compared to diabetic patients.

\section{Plasma CCK concentrations}

Fasting plasma CCK concentrations were not significantly different between the diabetic patients and the control subjects during euglycaemia and hyperglycaemia (Table 2). Infusion of $0.25,0.5$ and 1.0 IDU $\mathrm{kg}^{-1} \cdot \mathrm{h}^{-1}$ of CCK resulted in significant $(p<0.05)$ increases in plasma CCK concentrations over basal in all experiments. The plasma CCK concentrations in response to infusion of graded doses of CCK-33 were not significantly different between the diabetic patients and the control subjects (Table 2).

\section{Plasma PP concentrations}

Fasting plasma PP concentrations were not significantly different between the two experiments in the diabetic patients: $19 \pm 3 \mathrm{pmol} / \mathrm{l}$ (euglycaemia) and $23 \pm 7 \mathrm{pmol} / \mathrm{l}$ (hyperglycaemia) and in the control subjects: $20 \pm 3$ (euglycaemia) and $21 \pm 2$ (hyperglycaemia). In the patients plasma PP concentrations did not significantly change during the $60 \mathrm{~min}$ after initiating the clamp. At time 0 min plasma PP concentrations were $17 \pm 3 \mathrm{pmol} / \mathrm{l}$ (euglycaemia) and $19 \pm 4 \mathrm{pmol} / 1$ (hyperglycaemia). In the control subjects plasma PP concentrations decreased significantly $(p<0.05)$ from $21 \pm 2$ to $13 \pm 1 \mathrm{pmol} / 1$ at time 0 min during hyperglycaemia but remained in the same range during euglycaemia ( $20 \pm 3$ to $18 \pm 2 \mathrm{pmol} / \mathrm{l}$ at time $0 \mathrm{~min}$ ). Administration of $0.25,0.5$ and $1.0 \mathrm{IDU} \cdot \mathrm{kg}^{-1} \cdot \mathrm{h}^{-1}$ of CCK-33 resulted in significant increases in plasma PP concentrations in all experiments. The integrated incremental PP secretion in response to CCK is shown in Figure 4. In diabetic patients no significant differences between the experiments were observed. In the control subjects the PP secretion in response to CCK was significantly reduced during hyperglycaemia. 


\section{Plasma insulin concentrations}

Fasting plasma insulin concentrations were not significantly different between diabetic patients (hyperglycaemia $13 \pm 2 \mathrm{mU} / \mathrm{l}$; euglycaemia $14 \pm 2 \mathrm{mU} / \mathrm{l}$ ) and control subjects (hyperglycaemia $8 \pm 2 \mathrm{mU} / 1$; euglycaemia $13 \pm 2 \mathrm{mU} / 1$ ). To obtain euglycaemia in the diabetic patients a rise in insulin concentrations to $190 \pm 70 \mathrm{mU} / 1$ at time $-60 \mathrm{~min}$ was observed, due to the bolus insulin injections. During CCK infusion no significant differences in the plasma insulin concentrations were observed between the two experiments in diabetic patients. After initiating the hyperglycaemic clamp in the control subjects, plasma insulin levels increased significantly $(p<0.005-p<0.05)$ starting from time $-45 \mathrm{~min}$. At the end of the $15 \mathrm{mmol} / \mathrm{l}$ glucose clamp plasma insulin levels of $218 \pm 49 \mathrm{mU} / \mathrm{l}$ were reached.

\section{Plasma glucagon concentrations}

Fasting plasma glucagon concentrations were not significantly different between diabetic patients before euglycaemia $(107 \pm 16 \mathrm{pg} / \mathrm{ml})$ and before hyperglycaemia $(104 \pm 15 \mathrm{pg} / \mathrm{ml})$ and control subjects before euglycaemia $(98 \pm 9 \mathrm{pg} / \mathrm{ml})$ and before hyperglycaemia $(96 \pm 7 \mathrm{pg} / \mathrm{ml})$. No significant changes in plasma glucagon concentrations were observed in the diabetic patients or in the control subjects after stabilizing the plasma glucose concentrations at 5 and $15 \mathrm{mmol} / \mathrm{l}$ or in response to CCK infusion.

\section{Discussion}

Previous studies have suggested that in patients with diabetes fasting gallbladder volumes are increased $[7,26]$. However, other studies have not demonstrated significant differences in gallbladder volume between diabetic patients and control subjects $[10,11]$. The increase in fasting gallbladder volume, observed in some diabetic patients has been attributed to the presence of autonomic neuropathy [7]. In the diabetic patients we have studied and who had no clinical signs of autonomic neuropathy, fasting gallbladder volumes were not significantly different from healthy control subjects. In addition, fasting gallbladder volumes were not affected by the induction of euglycaemia or hyperglycaemia.

During euglycaemia CCK-induced gallbladder contraction in the diabetic patients was not impaired compared to control subjects. This observation is in accordance with the findings of a previous study [10]. Fiorucci et al. [10] have shown that CCK-induced gallbladder contraction in diabetic patients, even in patients with autonomic neuropathy, was not significantly different from control subjects. Stone et al. [9] found that CCKinduced gallbladder contraction in diabetic patients without neuropathy was not impaired, whereas in diabetic patients with autonomic neuropathy gallbladder contraction was significantly reduced. Using a meal as a stimulus, instead of CCK infusion, most investigators agree that gallbladder emptying in diabetic patients with autonomic neuropathy is reduced $[6,7]$. Since in these patients gastric emptying is often affected, a reduced gallbladder emptying may result from delayed gastric emptying of the meal.

To our knowledge the effect of acute hyperglycaemia on gallbladder contraction in diabetic patients has not been investigated before. In the studies reporting a reduced gallbladder contraction in response to CCK in diabetic patients, actual blood glucose concentrations during the study period were not recorded $[8,9]$. In the study of Stone et al. [9] no correlation was found between impaired gallbladder emptying in diabetic patients and overall glycaemic control as determined $\mathrm{HbA}_{1 \mathrm{c}}$ levels. However, in the present study we have shown that during a hyperglycaemia of $15 \mathrm{mmol} / \mathrm{l}$ the gallbladder contraction in response to infusion of $0.25 \mathrm{IDU} \cdot \mathrm{kg}^{-1} \cdot \mathrm{h}^{-1}$ of CCK, leading to plasma CCK levels as found after ingestion of a light meal, was significantly reduced in diabetic patients compared to euglycaemia. Plasma CCK levels reached during infusion of CCK were not significantly different between the experiments. It can therefore be excluded that differences in gallbladder emptying are related to differences in plasma CCK concentrations.

Apart from gallbladder motility, a relation between gastric emptying and hyperglycaemia has been demonstrated in recent studies in patients with Type 1 and Type 2 diabetes $[13,14]$. In these patients the gastric emptying of liquids and solids was significantly prolonged during hyperglycaemia compared to euglycaemia. The effect of hyperglycaemia on gastrointestinal function has been investigated more extensively in non-diabetic subjects. In healthy subjects acute hyperglycaemia inhibits gastrointestinal motility and secretion in response to various stimuli $[12,15,16,27-29]$.

Little is known, however, about the mechanisms responsible for the inhibitory effect of hyperglycaemia on gastrointestinal function. It is possible that metabolic, hormonal or neural changes secondary to hyperglycaemia rather than glucose itself modulate gastrointestinal function. In non-diabetic subjects high serum glucose levels stimulate insulin secretion and hyperinsulinaemia affects gastrointestinal function. Previous studies have shown however that insulin exerts a stimulatory rather than an inhibitory effect on gastrointestinal secretion and motility [30,31]. Furthermore hyperglycaemia reduces gastric and gallbladder motility in Type 1 diabetic patients, indicating that insulin is not responsible for the inhibitory effect of hyperglycaemia on gastrointestinal function. Glucagon is a potent inhibitor of intestinal motility [32]. However, in the present study no significant changes in plasma glucagon levels in the diabetic patients and 
S. Y. de Boer et al.: Gallbladder motility during hyperglycaemia in diabetes mellitus

in the control subjects were observed. Therefore, glucagon is not likely to be involved in the reduction in gallbladder motility during hyperglycaemia in diabetic patients and control subjects. Several arguments support an inhibitory effect of hyperglycaemia on gallbladder motility by suppressing activity of the vagal cholinergic system. First, the effect of CCK on the gallbladder in vivo is dependent on vagal-cholinergic activity [33]. Second, it has been shown in animals that infusion of glucose suppresses vagus nerve activity [34]. Third, in non-diabetic patients hyperglycaemia reduces basal and CCK-stimulated PP concentrations $[16,27,35]$. The release of PP from the pancreas is known to be under vagal cholinergic control [36]. Fourth, hyperglycaemia is known to suppress PP secretion through inhibition of vagal-cholinergic activity since the inhibitory effect of hyperglycaemia on PP secretion is blunted after truncal vagotomy [37]. Based on these observations it has been postulated that in non-diabetic patients hyperglycaemia affects gastrointestinal and gallbladder motility at least in part, through inhibition of vagal cholinergic activity.

It is not known whether this inhibitory mechanism also operates in diabetic patients. In contrast to the results in healthy subjects basal plasma PP levels and PP secretion in response to $\mathrm{CCK}$ infusion were not reduced during hyperglycaemia in diabetic patients. It has previously been shown that in diabetic patients plasma PP levels during hyperglycaemia are increased [38]. In contrast to healthy subjects, in diabetic patients plasma PP levels in response to a meal are independent of blood glucose concentrations [39]. Therefore, in diabetic patients PP secretion cannot be used as an indirect measure to evaluate the vagal cholinergic tone in response to hyperglycaemia.

Whereas in healthy subjects during an acute hyperglycaemia of $15 \mathrm{mmol} / \mathrm{l}$ gallbladder emptying was significantly reduced in response to infusion of $0.25,0.5$ and $1.0 \mathrm{IDU} \cdot \mathrm{kg}^{-1} \cdot \mathrm{h}^{-1}$ of CCK, in diabetic patients gallbladder emptying during hyperglycaemia at $15 \mathrm{mmol} / \mathrm{l}$ was significantly reduced only in response to infusion of $0.25 \mathrm{IDU} \cdot \mathrm{kg}^{-1} \cdot \mathrm{h}^{-1}$. The reason for this discrepancy in results between diabetic patients and nondiabetic subjects is not apparent but may be related to an adaptation to hyperglycaemia in diabetic patients.

It is concluded that in Type 1 diabetic patients without clinical signs of autonomic neuropathy 1) basal gallbladder volumes and fasting plasma CCK concentrations are not significantly different from healthy subjects either during hyperglycaemia or euglycaemia, 2) during euglycaemia the gallbladder contraction in response to CCK is not significantly different from healthy subjects, 3 ) hyperglycaemia significantly reduces the gallbladder contraction in response to infusion of only $0.25 \mathrm{IDU} \cdot \mathrm{kg}^{-1} \cdot \mathrm{h}^{-1}$ of CCK, whereas hyperglycaemia in control subjects significantly reduces the gallbladder contraction in response to $0.25,0.5$ and $1.0 \mathrm{IDU} \cdot \mathrm{kg}^{-1} \cdot \mathrm{h}^{-1}$ of $\mathrm{CCK}$.

\section{References}

1. Lieber M (1952) The incidence of gallstones and their correlation with other diseases. Ann Surg 135: 394-404

2. Stone BG, van Thiel DH (1985) Diabetes mellitus and the liver. Semin Liver Dis 5: 8-28

3. Hayes PC, Patrick A, Roulston JE, et al. (1992) Gallstones in diabetes mellitus: prevalence and risk factors. Eur J Gastroenterol Hepatol 4:55-59

4. Roslyn JJ, Pitt HA, Man LL, Ament ME, DenBesten L (1983) Gallbladder disease in patients on long-term parenteral nutrition. Gastroenterology 84: 148-154

5. Holan KR, Holzbach RT, Herman RE, Coopermann AM, Claffey WJ (1979) Nucleation time: a key factor in the pathogenesis of cholesterol gallstone disease. Gastroentero$\operatorname{logy} 72: 611-617$

6. Vogelberg KH, Kuebler HGW, Cicmir J, Rathman W (1984) Gallbladder contractility, cholelithiasis and autonomic neuropathy in diabetics. DMW 109: 1712-1715

7. Braverman DZ (1986) The lack of effect of metoclopramide on gallbladder volume and contraction in diabetic cholecystoparesis. Am J Gastroenterol 81: 960-962

8. Schreiner DP, Sarva RP, van Thiel DH, Yingvoparant N (1986) Gallbladder function in diabetic patients. J Nucl Med 27:357-360

9. Stone BG, Gaveler J, Belle S, et al. (1988) Impairment of gallbladder emptying in diabetes mellitus. Gastroenterology 95: $170-176$

10. Fiorucci S, Bosso R, Scionti L, et al. (1990) Neurohumoral control of gallbladder motility in healthy subjects and diabetic patients with or without autonomic neuropathy. Dig Dis Sci 35: 1089-1097

11. Keshavarian A, Dunne M, Iber LF (1987) Gallbladder volume and emptying in insulin requiring male diabetics. Dig Dis Sci 32: $824-828$

12. MacGregor IL, Gueller R, Watts HD, Meyer JH (1976) The effect of acute hyperglycaemia on gastric emptying in man. Gastroenterology 70: 190-196

13. Horowitz M, Harding PE, Maddox AF, et al. (1989) Gastric and oesophageal emptying in patients with type 2 (non-insulin-dependent) diabetes mellitus. Diabetologia 32: 151159

14. Fraser RJ, Horowitz M, Maddox AF, Harding PE, Chatterton BE, Dent J (1990) Hyperglycaemia slows gastric emptying in type 1 (insulin-dependent) diabetes mellitus. Diabetologia 33: 675-680

15. Øster-Jörgensen E, Pedersen SA, Larsen ML (1990) The influence of induced hyperglycaemia on gastric emptying in healthy humans. Scand J Clin Lab Invest 50: 831-836

16. De Boer SY, Masclee AAM, Jebbink MCW, et al. (1990) Effect of acute hyperglycaemia on gallbladder contraction induced by cholecystokinin in humans. Gut 34: 1123-1127

17. Ewing DJ, Clarke BF (1986) Autonomic neuropathy: its diagnosis and prognosis. Clin Endocrinol Metab 15: 855-888

18. DeFronzo RA, Tobin JD, Andres R (1979) Glucose clamp technique for quantifying insulin secretion and resistance. Am J Physio1 237: E214-E223

19. Hopman WPM, Kerstens PJSM, Jansen JBJM, Rosenbusch G, Lamers CBHW (1985) Effect of graded physiologic doses of cholecystokinin on gallbladder contraction measured by ultrasonography. Gastroenterology 89: 1242-1247

20. Everson GT, Braverman DJ, Johnson ML, Kern F (1980) A critical evaluation of real-time ultrasonography for the study of gallbladder volume and contraction. Gastroenterology 79: $40-46$ 
21. Hopman WPM, Brouwer WFM, Rosenbusch G, et al. (1985) A computerized method for rapid quantification of gallblader volume from real-time sonograms. Radiology 154 : 236-237

22. Jansen JBJM, Lamers CBHW (1983) Radioimmunoassay of cholecystokinin in human tissue and plasma. Clin Chim Acta 131: $305-316$

23. Jansen JBMJ, Lamers CBHW (1987) Molecular forms of cholecystokinin in plasma from normals and gastrectomized human subjects following a fat meal. Peptides 8: 801-805

24. Lamers CBHW, Diemel JM, van Leer E, van Leusen R, Peetoom J (1982) Mechanism of elevated serum pancreatic polypeptide concentration in chronic renal failure. J Clin Endocrinol Metab 55: 922-926

25. Nijs HGT, Radder JK, Fröhlich M, Krans HMJ (1990) In vivo relation between insulin clearance and insulin action in healthy subjects and insulin-dependent diabetic patients. Diabetes 39: 333-339

26. Bloom AA, Hackenfeld R (1969) Diabetic cholescintigraphy. JAMA 208: 357-359

27. De Boer SY, Masclee AAM, Lam WF, Lamers CBHW (1992) Effect of acute hyperglycaemia on esophageal motility and lower esophageal sphincter pressure in humans. Gastroenterology 103: 775-780

28. MacGregor IL, Deveney C, Way LW, Meyer JH (1976) The effect of acute hyperglycaemia on meal-stimulated gastric, biliary, and pancreatic secretion, and serum gastrin. Gastroenterology 70: 197-202

29. Niederau C, Sonnenberg A, Erckenbrecht J (1985) Effects of intravenous infusion of amino acids, fat or glucose on unstimulated pancreatic secretion in healthy humans. Dig Dis Sci 30: 445-455
30. Bueno L, Ruckebusch M (1987) Insulin and jejunal electrical activity in dog and sheep. Am J Gastroenterol 82: 840-843

31. Lee KY, Zhuo L, Ren XS, Chang TM, Chey WY (1990) An important role of endogenous insulin on exocrine pancreatic secretion in rats. Am J Physiol 258: G268-G274

32. Taylor I, Duthie HL, Cumberland DC, Smallwood R (1975) Glucagon and the colon. Gut 16: 973-978

33. Hopman WPM, Jansen JBMJ, Rosenbusch G, Lamers CBHW (1990) Role of cholecystokinin and the cholinergic system in intestinal stimulation of gallbladder contraction in man. Hepatology 11: 261-265

34. Hirano T, Niijima A (1980) Effects of 2-deoxy-D-glucose, glucose and insulin on efferent activity in gastric vagus nerve. Experientia 36: 1197-1198

35. Marco J, Hedo JA, Castillo-Olivares J, Villanueva ML (1980) Human pancreatic polypeptide secretion in conditions of exogenous and endogenous hyperglycaemia. Diabetologia 19: 418-422

36. Schwartz TW, Stenquist B, Olbe L (1979) Cephalic phase of pancreatic polypeptide secretion studied by sham feeding in man. Scand J Gastroenterol 14: 313-320

37. Tsuda K, Seino Y, Mori K, et al. (1981) Effect of truncal vagotomy on pancreatic polypeptide responses after intravenous glucose administration. Regul Rept 1: 347-352

38. Kennedy FP (1988) Pathophysiology of pancreatic polypeptide secretion in human diabetes mellitus. Diabetes, Nutrition and Metabolism 2: 155-163

39. Rasmussen MH, List S, Schwartz TW, Hilsted J (1990) Pancreatic polypeptide response to a meal is independent of glycaemic control. Diabetologia 33: A162 (Abstract) 